\title{
GREEN CORROSION INHIBITION OF MILD STEEL USING PRUNUS DULCIS SEEDS EXTRACT IN AN ACIDIC MEDIUM
}

FREDERICK OKHAKUMHE OSHOMOGHO, THELMA EJIRO AKHIHIERO, OSARIEMEN EDOKPAYI, AND JOY EHIMWENMA OSSAI.

(Received 5 March 2020; Revision Accepted 14 July 2020)

\begin{abstract}
Synthetic inhibitors use by industries often have adverse effect on the environment. This work therefore investigates the use of plant extract as an inhibition to mild steel corrosion in an acidic environment. Weight loss method was adopted to evaluate inhibition efficiency by plant extract as corrosion inhibitors. Almond seeds (Prunusdulcis) was extracted with the aid of Soxhlet apparatus. The corrosion inhibition experiment was performed by setting up reactors containing mild steel coupon with variable concentrations of plant extract and $200 \mathrm{ml}$ of $1.5 \mathrm{M} \mathrm{HCl}$ solution. The study revealed that the extract was an efficient inhibitor and was most effective as the concentration increased from $0.81 \%$ at $0.01 \mathrm{~g} / \mathrm{ml}$ to $69.95 \%$ at $0.15 \mathrm{~g} / \mathrm{ml}$ respectively. Adsorption study on mild steel surface showed that the experimental data fitted better into the Temkin isotherm with regression $\mathrm{R}^{2}$ closer to unity. Arrhenius constant and activation energy estimated at temperatures $308 \mathrm{~K}$ to $328 \mathrm{~K}$ revealed that activation energy $E_{a}$ increased with increasing inhibitor concentration from $5348.23 \mathrm{~J} / \mathrm{mol}$ at $0.01 \mathrm{~g} / \mathrm{ml}$ to $6151.44 \mathrm{~J} / \mathrm{mol}$ at $0.05 \mathrm{~g} / \mathrm{ml}$. The outcome of the study revealed that mild steel is susceptible to corrosionwhich is capable of destroying the material and increasing inhibitor concentration and temperature has significant influence on the corrosion.
\end{abstract}

KEYWORDS: Mild steel, Corrosion, Inhibitor, Plant Extract, Adsorption.

\section{$1.0 \quad$ INTRODUCTION}

Corrosion is the destruction of a material by a reaction which involves chemical, biochemical or electrochemical processes with the immediate environment. Metals generally tend to corrode as they always prefer to return to the stable oxide forms as a result of corrosion. An example is iron which returns to the oxide form when corroded (Rahuma et al., 2013).Mild steel easily gets corrodedby several minerals, organic materials, water and/or air in the soil (Akpofure and Kehinde2006). The different soil electrolytes contained in soil often results in fast corrosion rate of steel material due the complex materials in alloy (Rim-rukeh and Awatefe, 2006). Various factors influence the corrosion metals in soils such as $\mathrm{pH}$, oxidation reduction potential and residual microbes (Popoola et al.,2013).
Most synthetic inhibitors are organic compounds containing nitrogen, sulphur or oxygen atoms in their structures (Chigondo and Chigondo, 2016). The cost of these inhibitors is high and the inhibitor could be toxic to human and the Environment. This pestilent effects has created the desire for an environmentally friendly inhibitors as a replacement for the toxic synthetic inhibitors to promote greenness to the environment. These readily available plant derived green inhibitors are nontoxic, inexpensive and replenishing which can be extracted from various plant parts (Okafor et al., 2011; Oguzie et al.,2013). The used of plant extracts as inhibitors are vindicated by the phytochemical contents which have both electronic and molecular structures similar to the convention synthetic inhibitors(Oguzie et al.,2013). This investigation of the use of Prunusdulcis extract as a green corrosion inhibitor on mild steel in

Frederick Okhakumhe Oshomogho,Chemical Engineering Department, University of Benin, PMB 1154, Benin City, Nigeria. Thelma Ejiro Akhihiero, Chemical Engineering Department, University of Benin, PMB 1154, Benin City, Nigeria. Osariemen Edokpayi, Chemical Engineering Department, University of Benin, PMB 1154, Benin City, Nigeria. Joy Ehimwenma Ossai, Chemical Engineering Department, University of Benin, PMB 1154, Benin City, Nigeria. 
acidic medium involve the effects of temperature on the corrosion rate.

Mild steel has been a major metal often utilized in various industries including the petroleum industry because of its low cost and availability. However, this material is highly susceptible to various form of corrosion in the industries. Because of this problem, corrosion control has been a major challenge and synthetic corrosion inhibitors has been employ by many industries as an efficient method of corrosion control especially in acidic medium. These corrosion inhibitors has been massively used in the industry to prevent fast deterioration metal due to corrosion (Santhana et al., 2014).

Extracts from plants have proven to be active in the inhibition of metals corrosion and therefore a potential replacement for synthetic inhibitors as a result of successes achieved by several researchers (Yadav et al., 2016; Rahuma et al., 2013). The active ingredient as well as the structure of the green inhibitor determines the mechanism of action (Yadav et al., 2016). Several studies have reported that the active compounds in these plants extracts are adsorbed on the carthodic sites of the metal in acidic solution thereby interfering with the cathodic reaction which normally lead to corrosion (Rani and Basu 2012). The active constituents of natural inhibitors vary from one plant species to another but their structures are closely related to their organic counterparts (Chigondo and Chigondo, 2016). Mild steel corrosion inhibition by prunusdulcis has been previously reported by Shweta et al.(2018) where the extracts from the peels were experimentally investigated as a green corrosion inhibitor on mild steel.

Prunusdulcis (Almond) tree is one of the most common plant in places within the southern part of Nigeria and produced nuts that are easily consumed with refreshing taste (Olatidoye, et al., 2011).Almond plants are known to contain various phytochemicals such as phenolics, saponins, tannins, and flavonoids with organically active components like proanthocyanidins monomers, isorhamnetin-3-O-rutinoside and chlorogenic acid (Bolling, 2017;Mandalari, et al,2010). These compounds containheteroatomic components which help in adsorbing to metal surface thereby causing inhibition to corroding environment.The corrosion inhibition study of mild steel in acidic medium using the Prunusdulcis seed extract is a technological innovative approach. It will make the most economical methods of management and control of steel metal corrosion using very available plant material.

\subsection{MATERIALS AND METHOD}

\subsection{Plant Extract Preparation}

Almond seeds were oven dried for 4 hours at $80^{\circ} \mathrm{C}$ to reduce the moisture contents. The dried seeds were ground before extraction, using Soxhlet Apparatus with pure and analytical grade n-hexane as solvent. The extract was then freeze-dried to obtain concentrated, aqueous extracts.

\subsection{Preparation of Mild Steel Coupon}

The mild steel coupons of sizes $3 \mathrm{~cm} \times 8 \mathrm{~cm} \times 0.2 \mathrm{~cm}$ has a hole of about $0.1 \mathrm{~cm}$ drilled at one end to enable tying up with a nylon tread. They were then mechanically polished with silicon carbide abrasive paper, degreased with ethanol, washed in distilled water and dried in acetone.

\subsection{Thecorrosion experiment}

Corrosion inhibition experiment was conducted according to the method adopted by Gopal et al., (2011). Mildsteel coupons used in this experiment were accurately weighed with the aid ofan analytical balance with sensitivity of $\pm 0.1 \mathrm{mg}$. The coupons were totally immersed in $200 \mathrm{ml}$ solutions of $1.5 \mathrm{MHCl}$ in a $500 \mathrm{ml}$ beaker. The extract of the prunusdulcis seeds were thus added in various amounts in weight per volume from $0.01 \mathrm{~g} / \mathrm{ml}$, to $0.15 \mathrm{~g} / \mathrm{ml}$ and a control which did not contain the extract. Weight loss of the coupon was estimated at time intervals of 24 hours for a period of 5 days. This procedure was repeated at different temperatures of $30^{\circ} \mathrm{C}, 40^{\circ} \mathrm{C}$ and $50^{\circ} \mathrm{C}$. They were thoroughly washed with distilled water and then with $\mathrm{n}$-hexane to remove any waxy formation on the surface (Umoren, et al., 2010) and then reweighed. Weight loss was calculated from the difference in the weight of the mild steel coupons before immersion and after immersion into the test solutions (Equation 1).

$$
W_{t}=\frac{w_{a}-w_{b}}{w_{a}} \times 100
$$

Where $W_{t}$ is percent weight loss, $w_{a}$ is the initial weight of coupon and $w_{b}$ is the final weight of coupon.

\subsection{RESULTS AND DISCUSSION}

\subsection{Results of corrosion Study on Mild Steel}

Figure (1a) shows the efficiency of inhibition by the plants extract reduces as the number of hours increased in the corrosion reaction. This shows that effective inhibition is best operated by constantly replenishing the inhibitory plant extract.
Figure (1b) shows that the extract was most efficient as the concentration of inhibitor increases from $0.01 \mathrm{~g} / \mathrm{ml}$ to $0.15 \mathrm{~g} / \mathrm{ml}$. these results agrees with similar work done by Oguzie et al.,(2013). This can be attributed to the digestive capacity of the acid. Efficiency at 24 hours was highest and reduces correspondingly through 120 hours in the acidic medium. The nature of the inhibitor interaction with the corroding surface has been deduced 
from the adsorption characteristics of the inhibitor. Surface coverage $(\theta)$ values are much useful to measure the adsorption characteristics. The surface coverage of an inhibitor at any concentration is calculated using the equation (2). The measurements were performed at ambient temperature in the reactors.

$\theta=\frac{w_{0}-w_{i}}{w_{0}}$

$\eta_{w}=\frac{w_{0}-w_{i}}{w_{0}} \times 100$
All the experiments were performed in triplicate and average values were recorded. The concentration of inhibitor for weight loss study was taken in $\mathrm{mg} / \mathrm{l}$. The surface coverage $\theta$ (Equation 2) and inhibition efficiency $\eta_{w}(\%)$ (Equation 3) were determined according to Umoren et al., (2016)

Where $w_{i}$ and $w_{o}$ are the weight losses in presence and absence of inhibitor, respectively.

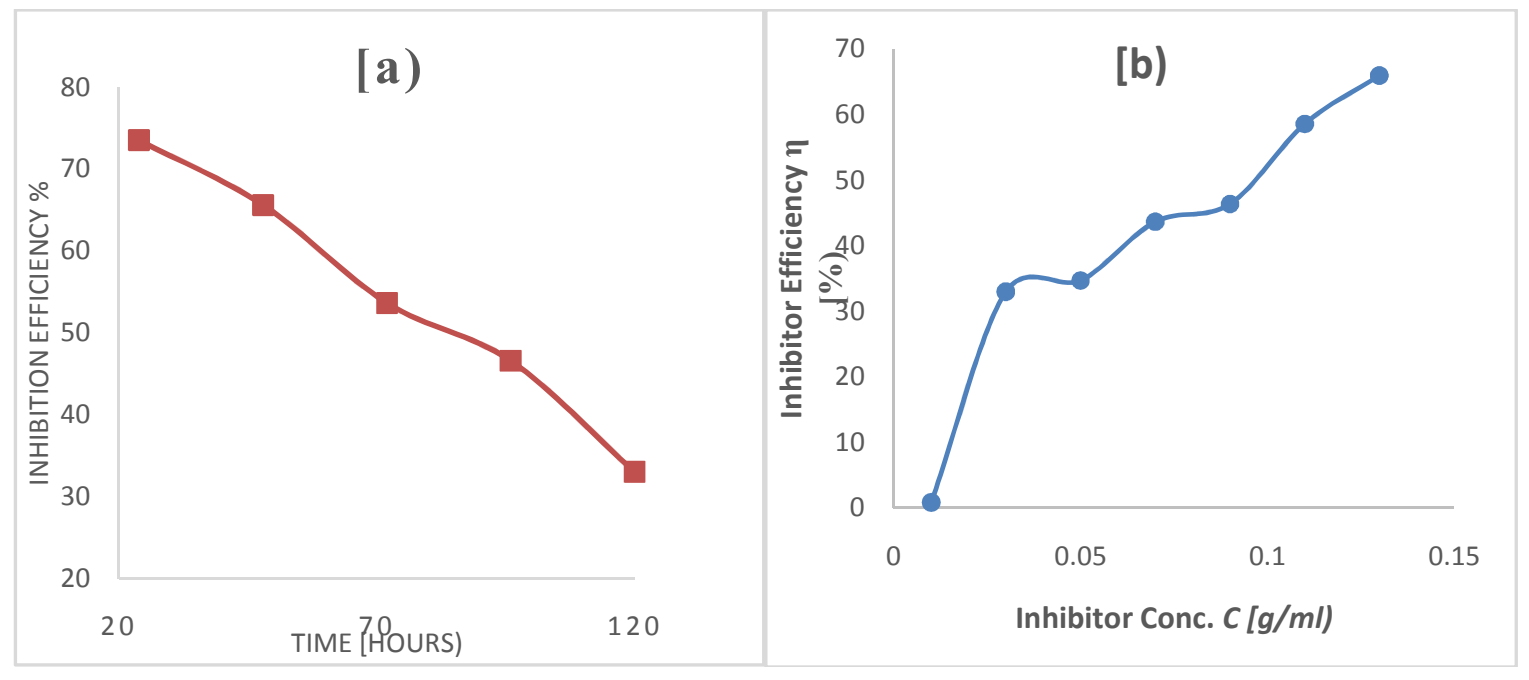

Figure 1: Inhibition efficiency of almond seed extract: (a) with time of immersion and (b) with concentration of inhibitor.

\subsection{Adsorption isotherm studies}

Adsorption isotherm was employed to understand the interaction between the inhibitor and metal surface. The degree of surface coverage $[\Theta]$ obtained from the weight loss studies was used to evaluate the best isotherm that fits into the information obtained. Langmuir and Temkin isotherm were employed to establish the isotherms most appropriate to the experimental data. The linear correlation coefficient with $\mathrm{R}^{2}$ values which is nearer to unity was taken to define the type of adsorption process. Langmuir adsorption process considered the interaction between the inhibitor molecules and the metal substrates and not between the inhibitor molecules.
The performance of the studied inhibitor may be attributed to the presence of electron donor atoms like $\mathrm{N}$ or $\mathrm{S}$ or $\mathrm{O}$ in the molecular structure of the inhibitor which favoured the greater adsorption of it on the metal surface (Dada et al., 2012). Several attempts were made to fit various isotherms. In the present study, the experimental data were best fitted by Langmuir and Temkin adsorption isotherms.

\subsection{Langmuir Adsorption Isotherm}

The Langmuir isotherm is presented in equation (4) according to Nwabanne and Okafor (2012).

$$
\frac{C}{\theta}=\frac{1}{K}+C
$$

Where

$C$ is the inhibitor concentration, $\theta$ is the degree of surface covered by the inhibitor, and $\mathrm{K}$ is the adsorption equilibrium constant. A plot of $\frac{C}{\theta}$ versus $\mathrm{C}$ yields a 
linear relationship where the slop is unity and the constant as the intercept. The inhibitor is said to be strongly adsorbed if the adsorption equilibrium constant is large. The slope is near unity because each inhibitor molecule is adsorbed on an individual active site on the metal

surface

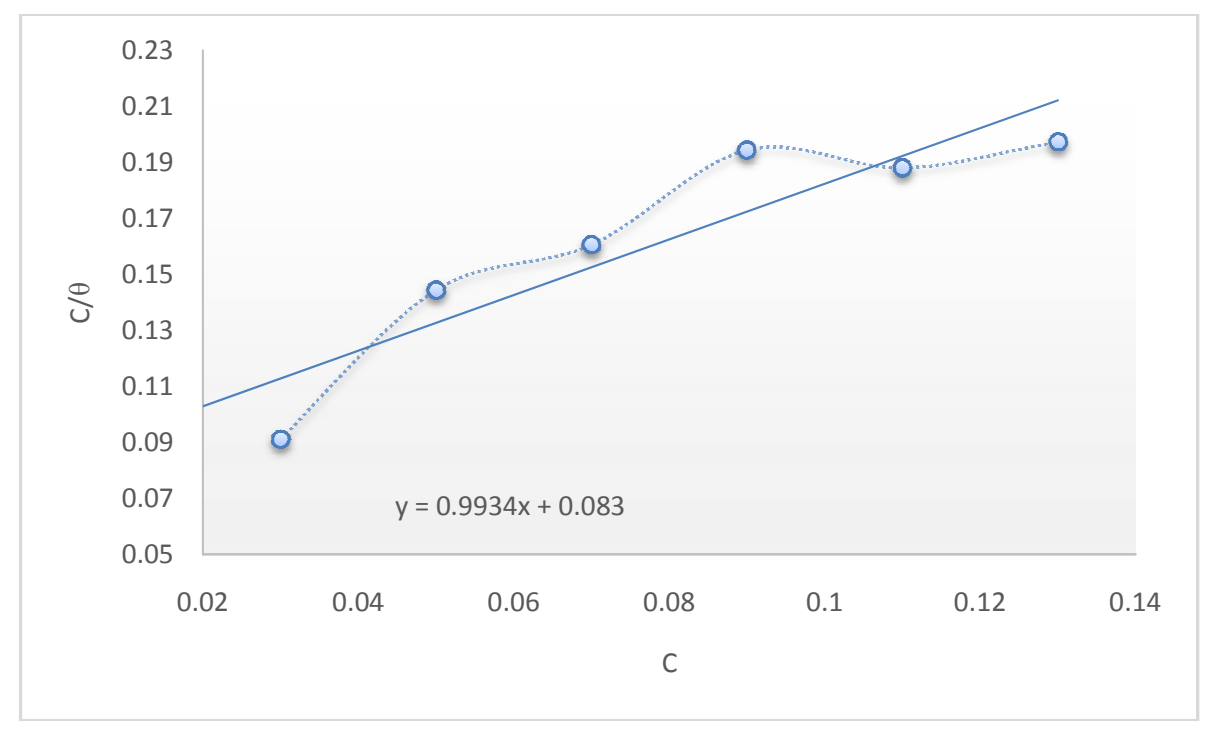

Figure 2: Langmuir adsorption isotherm

This explains that the adsorption of the inhibitor molecules on the mild steel surface is reliable on
Langmuir adsorption isotherm model and the correlation coefficient $\left(R^{2}\right)$ obtained are near to unity.

\section{Table 1: Langmuir isotherm constant values}

\begin{tabular}{|l|l|}
\hline$K$ & $R^{2}$ \\
\hline 12.048 & 0.832 \\
\hline
\end{tabular}

\subsection{Temkin adsorption isotherm}

This isotherm contains a factor that very well considers the interactions between adsorbent and adsorbate. By ignoring the extremely low and large value of concentrations, the model assumes that heat of adsorption (function of temperature) of all molecules in the layer would decrease linearly rather than logarithmic with coverage (Umoren et al., 2016). As implied in the equation, its derivation is characterized by a uniform distribution of binding energies [up to some maximum binding energy] was carried out by plotting the quantity of surface coverage $\theta$ against $\log C$ and the constants were determined from the slope and intercept. The model is given by the following equation according Dada et al.,(2012). Temkin isotherm model explicitly takes into account the interaction between adsorbate and adsorbent(Umoren et al., 2016). It assumes that fall in heat of adsorption is linear rather than Logarithmic. The equation can be expressed as in equation (5):

$$
\theta=-\frac{2.303 \log K}{2 a}-\frac{2.303 \log C}{2 a}
$$

$\mathrm{K}$ is the adsorption equilibrium constant and, "a" is the attractive parameter. The $\theta$ and log $C$ are amount of adsorbed dissolved solids per unit weight of adsorbent and unadsorbed dissolved solid concentration in solution at equilibrium, respectively. A plot of $\theta$ vslog $\mathrm{C}$ yields a linear relationship where slop is $-\frac{2.303}{2 a}$ and intercept will be $-\frac{2.303 \log K}{2 a}$. The value of 'a' should be negative to show that repulsion occurred in the adsorption layer. 


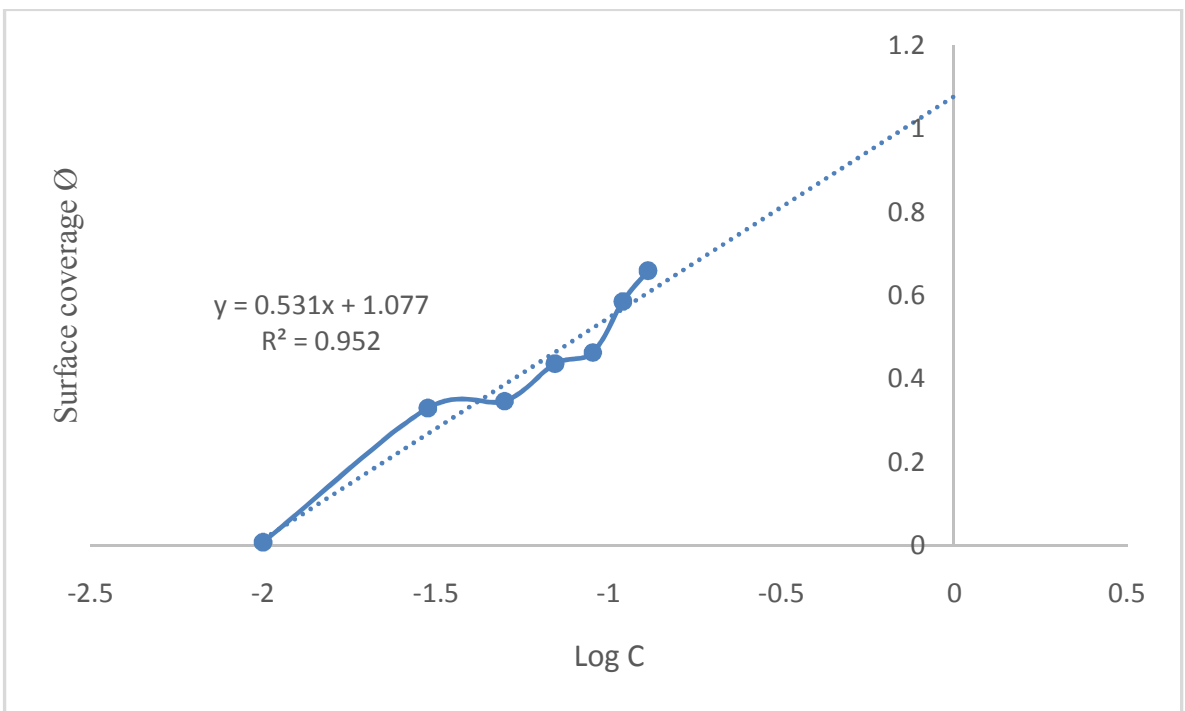

Figure 3: Temkin adsorption isotherm plot at $30^{\circ} \mathrm{C}$

From the Temkin plot shown in Figure 3, the following values were estimated: ' $a$ ' $=-2.167 \mathrm{~L} / \mathrm{g}, \mathrm{K}=$ sorption indicating a physical adsorption process and $0.00959 \mathrm{~J} / \mathrm{mol}$ which is an indication of the heat of the $R^{2}=0.9528$.

Table 2: Temkin isotherm constant values

\begin{tabular}{|l|l|l|}
\hline $\mathrm{K}$ & $\mathrm{a}$ & $\mathrm{R}^{2}$ \\
\hline 0.00959 & -2.167 & 0.9528 \\
\hline
\end{tabular}

By comparison of the degree of linearity of the adsorption isotherms by the values of $R^{2}$ (Tables 1 and 2 ), It was observed that Temkin isotherm best fitted at temperature of $303 \mathrm{~K}$ than at $333 \mathrm{k}$. This confirm the strong influence of temperature on the adsorption behaviour of inhibitor.

The slope at $303 \mathrm{~K}$ are greater than the values obtained at $333 \mathrm{~K}$, indicating that the strength of the attractive behaviour of the inhibitor decreases with temperature. The strength of the attractive behaviour of the inhibitor was deduced from the values of slope obtained at $303 \mathrm{~K}$ which were obviously greater than that obtained at 333 K (Unueroh et al., 2016).

\subsection{Rate of Corrosion}

The corrosion rate $\left(C_{R}\right)$ of mild steel was calculated using (Equation 6) the relation according to Cang et al.,(2012):

$$
C_{R}=\frac{k w}{A t \rho}
$$

Where $\mathrm{k}$ is weight loss constant $87.6 \mathrm{mdd}, \mathrm{w}$ is corrosion weight loss of mild steel (mg), A is area of the coupon 2.0 by $4.0 \mathrm{~cm}$, $t$ is exposure time ( 24 hours), and $\rho$ is the theoretical density of mild steel (low-carbon steel) $\left(7.85 \mathrm{~g} / \mathrm{cm}^{3}\right)$ from engineering tool box (2020).

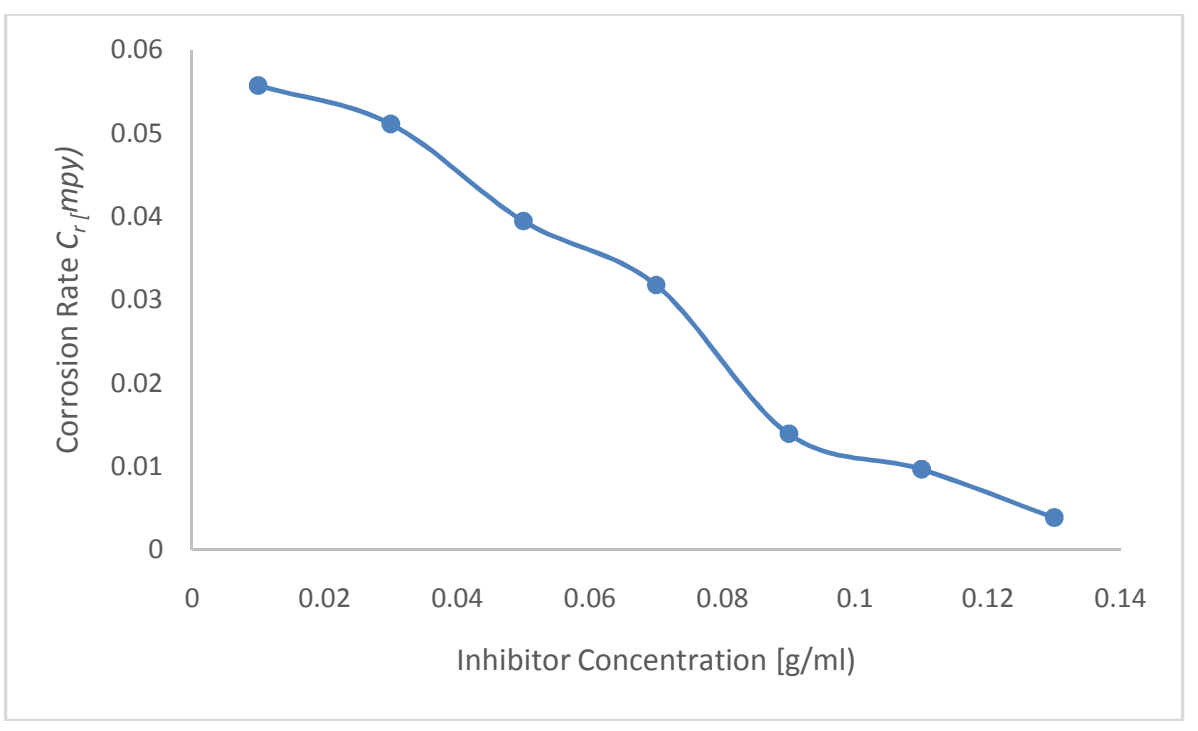


It was observed from Figure (4) that increasing the concentration of inhibitor results in the decrease of the corrosion rate of mild steel at ambient temperature of about $30^{\circ} \mathrm{C}$.

\subsection{Effects of temperature on inhibition efficiency} Analysis of the temperature dependence of inhibition efficiency, corrosion rate as well as activation energies in the absence and presence of the inhibitor gives some insights into the possible mechanism of inhibitor adsorption. In order to evaluate the adsorption of inhibitors and to calculate thermodynamic and activation parameters of the corrosion processes of the mild steel in acidic media, the effect of temperature on the corrosion parameters was studied using the weight loss technique. Measurements were made in the temperature range $303 \mathrm{~K}$ to $328 \mathrm{~K}$ with inhibitor concentrations of $0.01,0.03$ and $0.05 \mathrm{~g} / \mathrm{ml}$ during the total immersion period. Activation parameters for some systems can be estimated from an Arrhenius-equation (Equation 7).

$k_{C R}=A \exp \left(-\frac{E_{a}}{R T}\right)$
$k_{C R}$ is the corrosion rate and $A$ is frequency factor also referred to as the pre-exponential factor. $E_{a}$ is the activation energy in $\mathrm{Jmol}^{-1}, \mathrm{R}$ is gas constant in $\mathrm{Jmol}^{-1} \mathrm{~K}^{-}$ 1 while $T$ is absolute temperature in kelvin $(K)$. The values of activation energies and frequency factors were estimated from the linearization of Equation(7) which produced equation(8).

$\log k_{C R}=\log A-\frac{E_{a}}{R T}$

Inspection of the data shows the corrosion rate of mild steel increased with increase in temperature. The increase in corrosion rate is more pronounced for the uninhibited acid solutions (Figure 5). Increasing inhibitor concentration was observed to decrease corrosion rate. The effects of increase in temperature was significant as the rate of corrosion rose from 0.06 mddat $303 \mathrm{~K}$ to $0.095 \mathrm{mdd}$ at $328 \mathrm{~K}$. The uninhibited had the highest corrosion thereby proving the efficiency of the inhibitor. The observed efficiency with increase in temperature is an indication that some of the extract components become more adsorbed at higher temperature and so contribute more to the overall inhibiting effect.

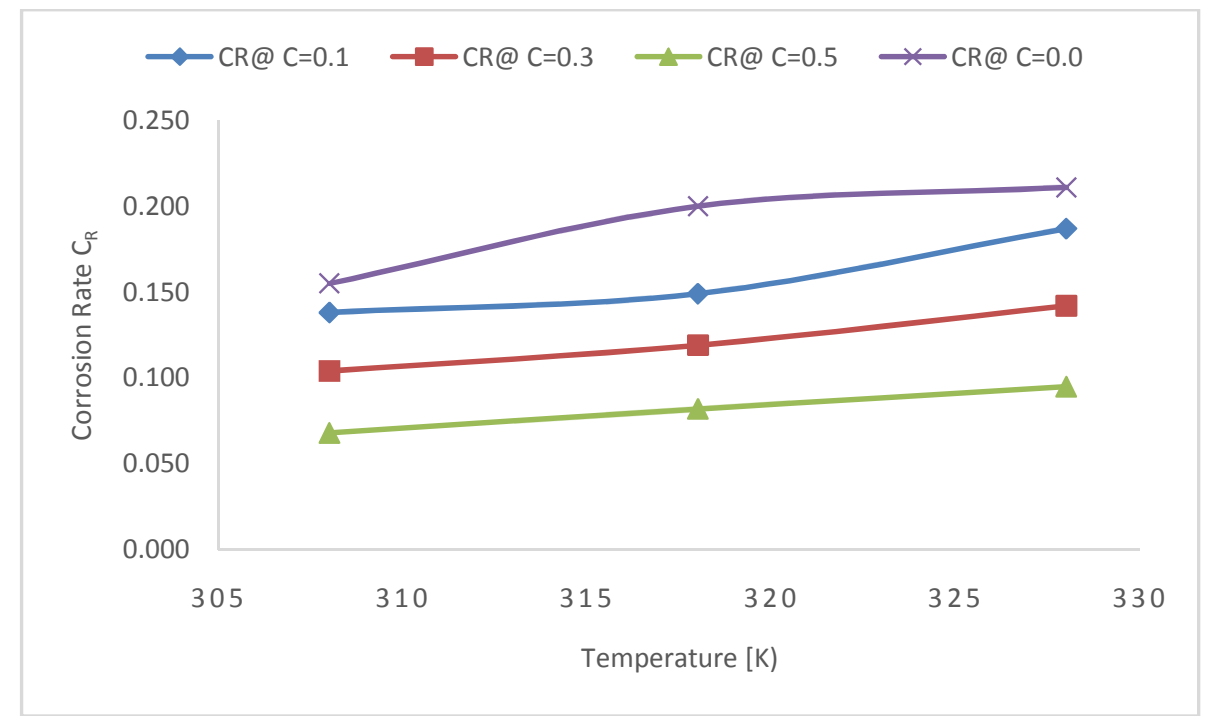

Figure 5: Effects of increasing temperature with concentration of inhibitor on the rate of corrosion.

The study of corrosion rate and kinetic parameters are of importance in the control of corrosion. From the Arrhenius equation (Equation 8), the activated energy can be estimated.

The study of corrosion kinetics includes the investigation of different experimental conditions impact on the chemical reaction rate and thus provides information about the mechanism of the reaction as well as the construction of a mathematical model which is capable of describing the character of the reaction (Oguike,2014).Data of corrosion rate with respect to the acid concentration can be used to prove the rate dependence of the acid concentration. The kinetic and thermodynamic parameters were estimated from the following equations (7) and (8) respectively (Oguike,2014). 


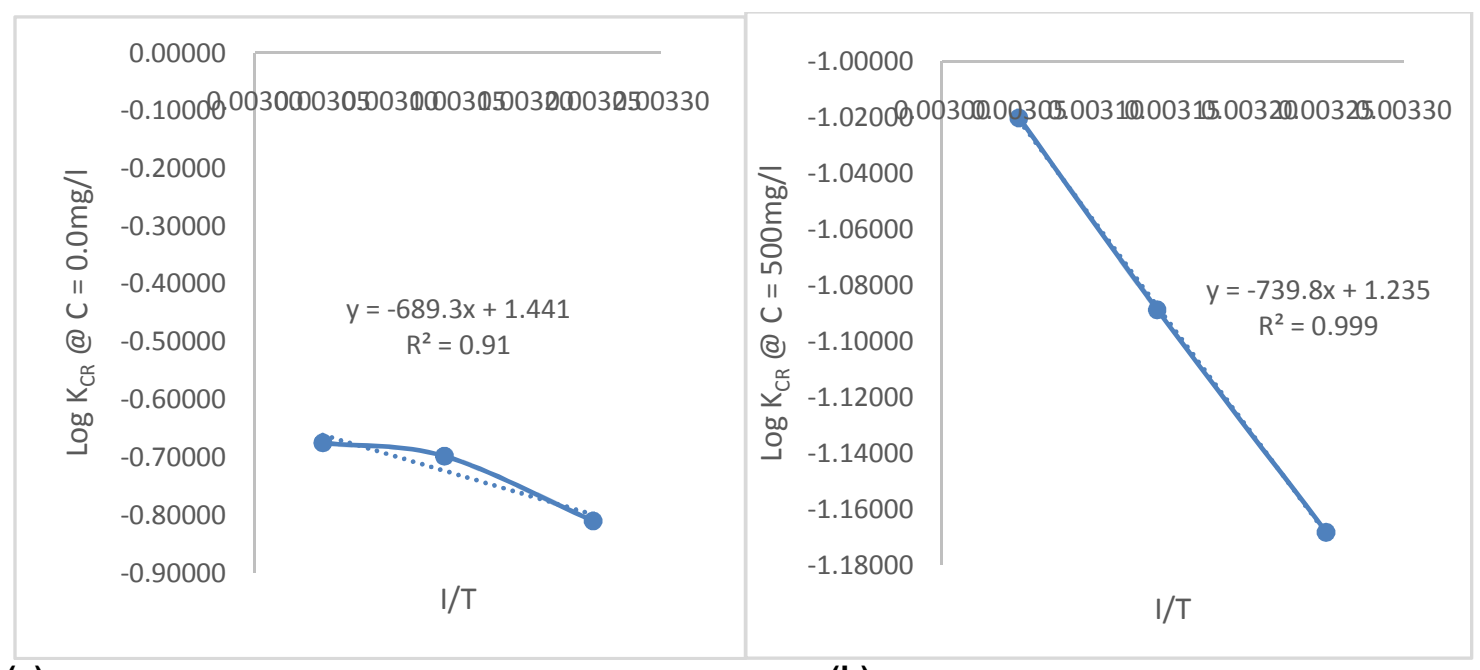

(a)

(b)

Figure 6: Corrosion rate constant at inhibitor concentration of 500mg/l inhibitor concentrations respectively.

The effects of almond seed extract inhibitor on the activation energy in the corrosion process is shown in Figure 6. From the Arrhenius plot, the Arrhenius constant and activation energy can be determined. The activation energy $E_{a}$ increases with increasing inhibitor concentration. Therefore, that there is a strong surface interactions with a corresponding frequency factor $A$ increase. The values of $A$ were obtained from the $y$ intercept of the Arrhenius plots while $E_{a}$ was obtained using the slope.

\section{Table 3: Kinetic parameters of corrosion rate constant}

\begin{tabular}{|l|l|l|l|}
\hline Rate Constant & $\mathbf{A}$ & $\mathbf{E}_{\mathrm{a}}(\mathrm{J} / \mathrm{mol})$ & $\mathbf{R}^{2}$ \\
\hline $\mathrm{k}_{\mathrm{CR}} @ 0.0 \mathrm{mg} / \mathrm{l}$ & 27.61 & 5731.26 & 0.9100 \\
\hline $\mathrm{k}_{\mathrm{CR}} @ 5000 \mathrm{mg} / \mathrm{l}$ & 17.211 & 6151.44 & 0.9998 \\
\hline
\end{tabular}

Table 3 summarizes the results for all concentrations of inhibitor. Inspection of the table reveals that the introduction of inhibitor causes an increase in the activation energy from the blank case of $5731.26 \mathrm{~J} / \mathrm{mol}$. The activation energy is the amount required for the corrosion reaction to proceed. Thus, the increase in magnitude of $E_{a}$, with the inhibitor concentration, indicates that it is more difficult for the corrosion reaction to proceed. Higher values of $E_{a}$ are a good indication that almond seed extract provides strong inhibitive action through raising the energy barrier of the corrosion process. The increase of the $E_{a}$ can be attributed to the presence of the almond seed extract which increases the thickness of the double layer. The overall trend for almond seed extract is that as the concentration increases, the activation energy increases.

\section{CONCLUSION}

This study provides investigation on the effects of the almond seed extracts on the inhibition of corrosion caused by acidity in a medium. The outcome of the investigation has revealed that mild steel is susceptible to acidic mediumwhich is capable of corroding the material.

The inhibition process has shown that all inhibitor concentrations significantly reduces the corrosion as was evident in the weight loss estimation.

The surface interaction between the mild steel and the inhihitnr actimated hy I anamı ir and Termkin adcorntinn isotherms revealed that Temkin fitted better with the experimental data obtained with a higher regression value.

Increasing the temperature of the corrosion medium was also observed to result in increase in corrosion rate but with corresponding increase in inhibition efficiency indication that some of the extract components become more adsorbed at higher temperature and so contribute more to the overall inhibiting effect. The overall trend for almond seed extract is that as the concentration increases, the activation energy for the corrosion increases.

\section{REFFERENCES}

Bolling, B. W., 2017. Almond Polyphenols: Methods of Analysis, Contribution to Food Quality, and Health Promotion, Comprehensive Revision. F. Sci. F.Safety. 16:346-368

Cang H., Zhenghao F., Hairong X., Jiali H. and Qi X., 2012.Inhibition Effect of Reed Leaves Extract on Steel in Hydrochloric Acid and Sulphuric Acid Solutions. Inter. J. Electrochem. Sci., 7: 8869 8882.

Chigondo M. and Chigondo F., 2016. Recent Natural Corrosion Inhibitors for Mild Steel: An Overview. J. Chem. 2: 7 
Dada A. O, Olalekan A. P, Olatunya A. M., and DADA O., 2012. Langmuir, Freundlich, Temkin and Dubinin-Radushkevich Isotherms Studies of Equilibrium Sorption of $\mathrm{Zn}^{2+}$ Unto Phosphoric Acid Modified Rice Husk. IOSR J. App. Chem. [IOSR-JAC]. 3: 38-45

Gopal J. I., Sudhish Kumar Shukla, Priyanka Dwivedi, Shanthi Sundaram, and Rajiv Prakash 2011. Inhibitive Effect of Argemonemexicana Plant Extract on Acid Corrosion of Mild Steel. |Ind. Eng. Chem. Res.50:11954-11959

Mandalari, G., Tomaino, A., Arcoraci, T., Martorana, M., Turco, V. Lo., Cacciola, F., Rich, G.T., Bisignano, C., Saija, A., Dugo, P., Cross, K. L., Parker, M. L., Waldron, K. W., Wickham, M. S. J.,2010. Characterization of polyphenols, lipids and dietary fibre from almond skins (Amygdaluscommunis L.), J. Food Com. Anal. 23: 166-174.

Nwabanne J., Tagbo, O., and Nwoye V., 2012. Adsorption and Thermodynamics Study of the Inhibition of Corrosion of Mild Steel in $\mathrm{H}_{2} \mathrm{SO}_{4}$ Medium Using Vernoniaamygdalina. J. Min. Mater. Charac. Eng., 11:885-890

Oguike R. S., 2014. Corrosion Studies on Stainless Steel (FE6956) in Hydrochloric Acid Solution. Adv. Mat. Phy. Chem.,4:153-163

Oguzie E. E., Akalezi C. O. and Enenebaku C. K., 2013. Inhibition of acid corrosion of mild steel by biomass extract from the petersianthusmacrocarpusplant. J. Mater. Environ. Sci.4(2):217-226

Okafor P. C., Liu C. B., Zhu Y. J., and Zheng Y. G., 2011. Corrosion and corrosion inhibition behaviour of $\mathrm{N} 80$ and P110 carbon steels in $\mathrm{CO}_{2}$ saturated simulated formation water by rosin amide imidazoline. Ind Engng and Chem Res. 50:7273-7281

Olatidoye, O. P, Sobowale S. S, Akinlotan, J. V and Olorode, O. O., 2011. Chemical composition and physicochemical characteristics of tropical almond nuts (terminaliacatappia I) cultivated in South West Nigeria. J. Med. App. Biosci. 2.

Popoola L. T, Grema S., Latinwo K. G., Gutti B. and Balogun A. S., 2013. Corrosion problems during oil and gas production and its mitigation. Inter. J. Ind. Chem. 4:1-15.

Rahuma M. N., EL-Sabbah M. B., Hamad I. M., 2013. Effect of serine and methionine on electrochemical behavior of the corrosion of mild steel in aqueous solutions. Hindawi Pub. Corp. ISRN. 1-7.
Raja P. B. and Sethuraman M. G.,2008.Inhibitive effect of black pepper extract on the sulphuric acid corrosion of mild steel. Mater Letters.62:29772979

Rani B. E. Amitha and Basu Bharathi Bai J.,2012. Green inhibitors for corrosion protection of metals and alloys: an overview. Inter. J Corr, $2: 15$.

Rim-rukeh, A. and Awatefe, J. K., 2006. Investigation of Soil Corrosivity in the Corrosion of Low Carbon Steel Pipe in Soil Environment. J. App. Sci. Res.2(8): 466-469.

Santhana P. S., Joseph R. R., Dorothy R., Brindha G., and Pandiarajan M., 2014. Corrosion problems in petroleum industry and their solution. Eur. Chem. Bull. 3: 300-307.

Shweta P., Hassane L., Preeti T., Chung M., Gopal J., and Rajiv P., 2018. Experimental and theoretical investigation of aqueous and methanolic extracts of Prunusdulcis peels as green corrosion inhibitors of mild steel in aggressive chloride media. Journal of Molecular Liquids. https://doi.org/10.1016/j.molliq.2018.11.099. Accessed Jan. 12, 2020.

The Engineering Tool Box., 2020. Density of some common metals, metallic elements and alloys. https://www.engineeringtoolbox.com/metalalloys-densities-d_50.html. Accessed $12^{\text {th }}$ Jan. 2020.

Umoren S. A., Eduok U. M., Solomon M. M., and Udoh A. P., 2016. Corrosion inhibition by leaves and stem extracts of Sidaacuta for mild steel in $1 \mathrm{M}$ $\mathrm{H}_{2} \mathrm{SO}_{4}$ solutions investigated by chemical and spectroscopic techniques. Arab. J. Chem.9: 209-224.

Umoren, S. A., Solomon, M. M., Udosoro, I. I., and Udoh, A. P., 2010. Synergistic and antagonistic effects between halide ions and carboxymethyl cellulose for the corrosion inhibition of mild steel in sulphuric acid solution. J. Cellulose.17: 635648.

Unueroh U., OmonriaG., Efosa O., and Awotunde M., 2016. Pipeline corrosion control in oil and gas industry: a case study of NNPC/PPMC system 2a pipeline. $35: 317-320$

Yadav M., Gope L., Kumari N., and Yadav P., 2016. Corrosion inhibition performance of pyranopyrazole derivatives for mild steel in $\mathrm{HCl}$ solution: gravimetric, electrochemical and DFT studies. Journal of Molecular Liquids. 216: 7886. 